\title{
EFFECTS OF EXPERIMENTAL HYPERTONIA ON CIRCULATING LEUKOCYTES ${ }^{1}$
}

\author{
By JAMES L. TULLIS 2 \\ (From the Department of Biological Chemistry, Harvard Medical School, and the Laboratory \\ of Pathology of the New England Deaconess Hospital, Boston)
}

(Received for publication May 5, 1947)

During the 50 years that have elapsed since Arneth originally studied the behavior of circulating leukocytes, many substances and physical factors have been shown to exert an effect of either depressing or stimulating the total numbers of circulating white cells. Most of the substances have been protein in nature. Thus bacterial products (1), peptone (2), enzymes (3), tissue extracts (4), and pseudoglobulins (5), have all been shown to cause temporary alteration in the peripheral leukocyte picture. Among the physical factors that can similarly influence white cell circulation are cold (6) and ultraviolet light (7). Boyd (8), in 1913, was the first to show that inorganic ions can stimulate an increase in the total white count. While treating insanity with intravenous salt solution, he noted an increase in the polymorphonuclear cells of the blood. Later Bluemel and Lewis (9), in 1924, were able to demonstrate a transitory leukocytosis under the same circumstances. Beard and Beard (10), in 1928, working with rabbits, showed that the intravenous injection of salt caused a transitory leukopenia followed by a leukocytosis. They postulated that the cation $\mathrm{Na}^{+}$might play some role in regulation of white counts.

While working with leukocyte tissue cultures, it was observed (11) that polymorphonuclear neutrophiles exhibited a lengthened survival in hypertonic media whereas lymphocytes showed a corresponding slightly lengthened survival in hypotonic media. Although such studies dealt solely with cell survival, they raised interesting possibilities of correlation with in vivo effects on regulation of circulating leukocytes. The present study was therefore undertaken to determine whether simple alteration in the tonicity of serum would similarly effect leukocyte maturation and

\footnotetext{
1 The author is indebted to Miss Jean Sunderlin for technical assistance.

2 Donner Foundation, Research Fellow.
}

release into the peripheral circulation. That is: would experimental hypertonicity induce a selective polymorphonuclear leukocytosis?

\section{METHODS}

Subjects: Healthy 10- to 14-kilogram dogs. Hypertonicity was induced, both acutely and chronically, by diverse means. Prior to the start of any 1 experiment, the animals were maintained on a standard diet and fluid intake for 1 week. In experiments which extended over a several-day period, all blood studies were done at the same time of day, under the same circumstances and by the same set of observers, to minimize, as far as possible, the effects of activity, excitement and variation in the diurnal tide on the peripheral leukocyte pattern. Total white counts and smears were made with standard techniques. Red cell counts and/or hematocrits were done throughout each experiment. All variations in absolute leukocyte counts were thus corrected for the fattor of hemoconcentration. All variations in tonicity of the extracellular fluid were determined by the technique of freezing point depression on defibrinated blood and are reported in milliosmoles per liter (conversion factor: $\Delta \mathrm{T}_{\mathrm{s}}=1.86 \mathrm{M}$ ).

\section{CHRONIC HYPERTONICITY}

Chronic hypertonicity was attained over a 5- to 10-day period by the following means: (1) Chronic water and food deprivation; (2) chronic water deprivation in the presence of a dry protein diet; (3) chronic water deprivation in the presence of a dry protein diet plus hypertonic salt solution parenterally. As shown by Danowski (12), and others, the diuretic effect of the end products of nitrogen metabolism hastened the onset of chronic hypertonia. Chronic hypertonia was effected 1 time on each of 3 seperate dogs, " $A$," "C" and " $F$."

\section{RESULTS}

The average resting (pre-experimental) molarity was 308 milliosmoles. The levels of hypertonicity that were attained varied from 364 to $484^{3}$ milliosmoles. In each instance the hyper-

8 When this exceptionally high molarity was reached the dog (Exp. A-2) was in extremis and convulsing. Immediately after the tests' were made, the dog was successfully revived by large amounts of hypotonic fluid i.v. 
tonicity was accompanied by an increase in the absolute numbers of circulating neutrophiles. The lymphocytes and eosinophiles remained essentially unchanged. The absolute numbers of monocytes decreased. In Figures 1 and 2, the increase in absolute neutrophile counts are plotted against the rise in molarity which occurred in each of the 3 experiments, A-2, C-1, F-1. It will be seen that the molarity of the serum and the absolute neutrophile count bore a linear relation to one another. Under the experimental conditions which existed, the absolute numbers of circulating polymorphonuclear neutrophiles appeared to be a factor of the tonicity of the extracellular fluids.

\section{ACUTE AND CHRONIC HYPERTONIA EXPERIMENTS $A-3, C-1, F-1$}

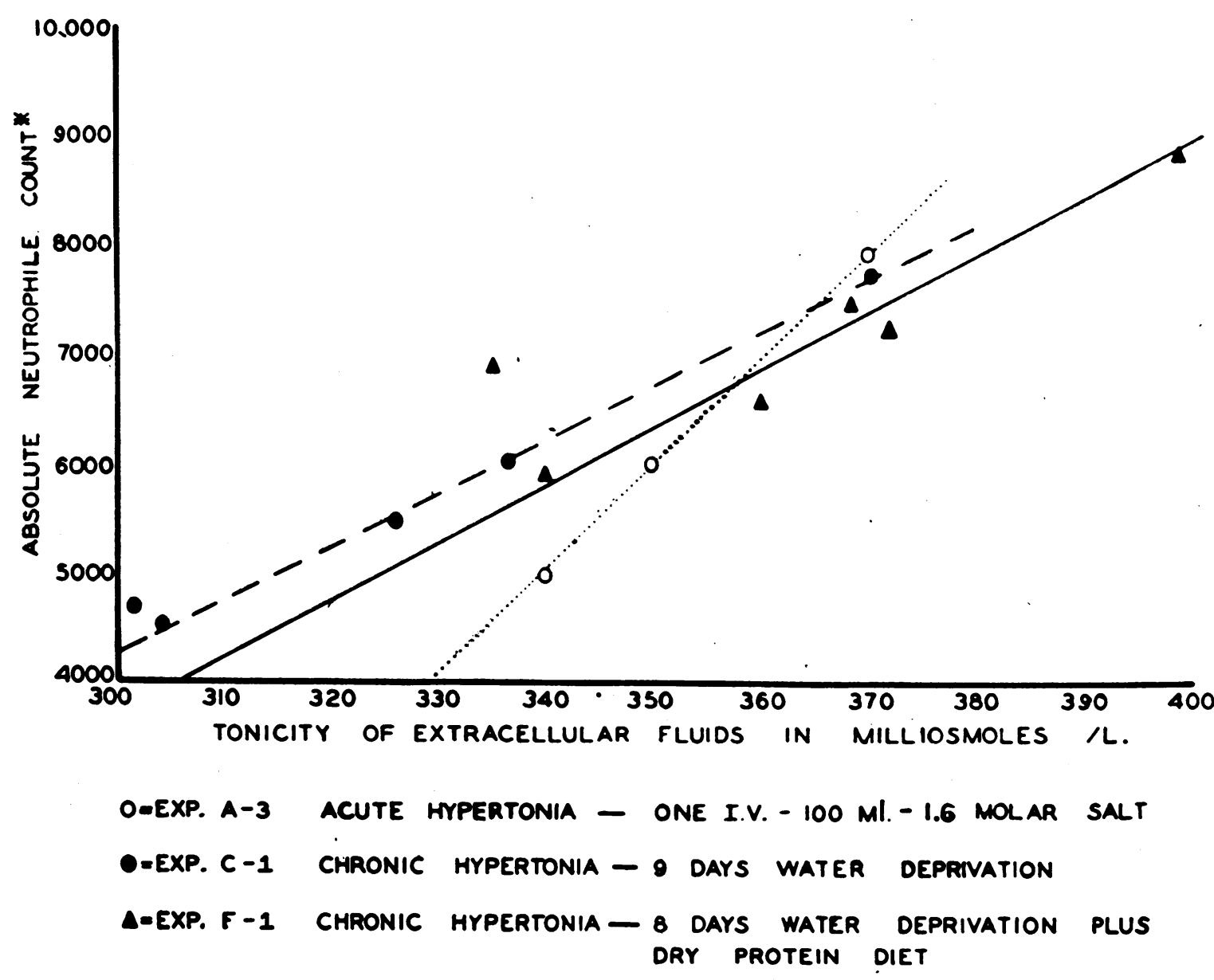

CORRECTED FOR HEMOCONCENTRATION

FIG. 1. 


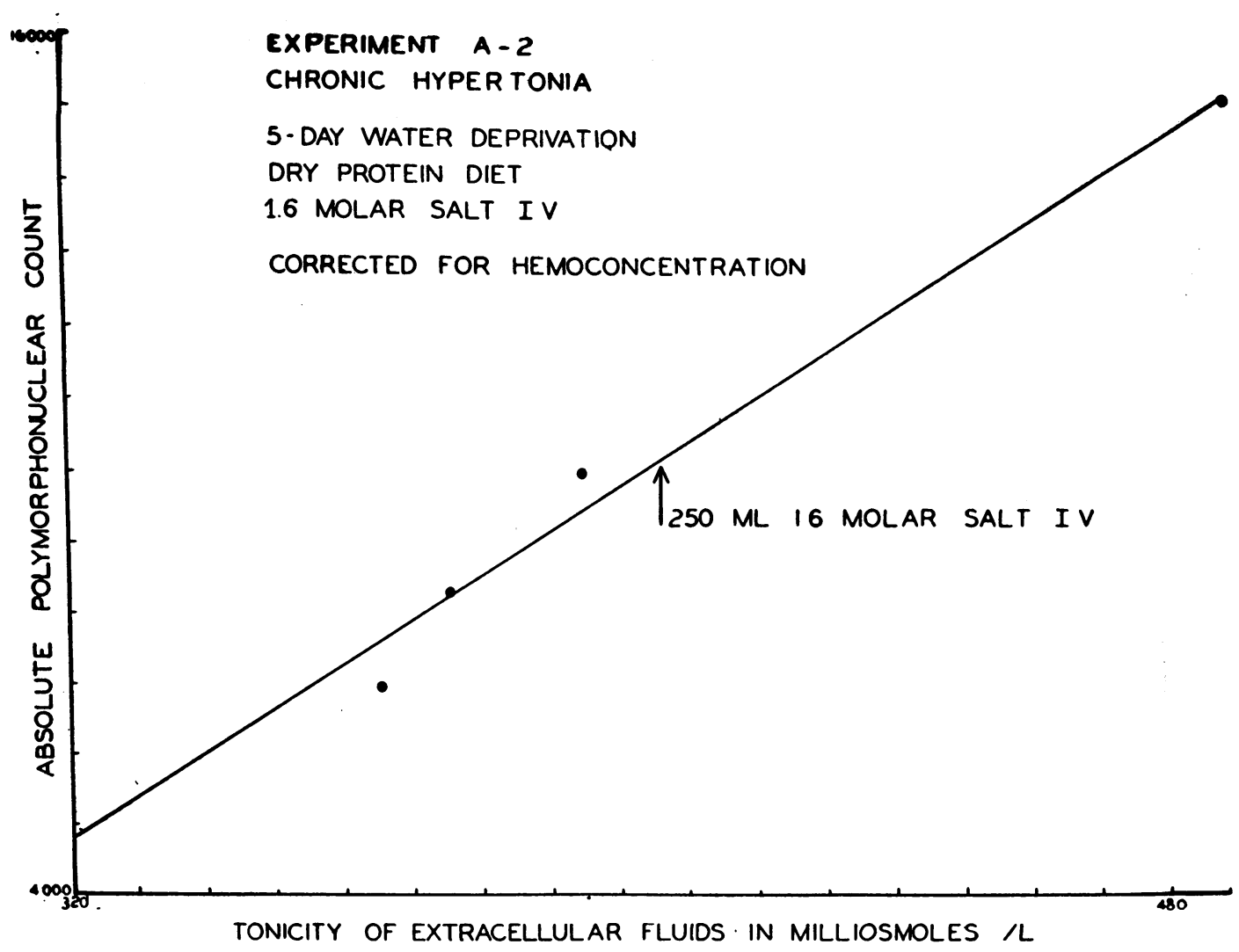

Fig. 2.

\section{ACUTE HYPERTONICITY}

Acute hypertonicity was produced, in all instances, by the intravenous administration of hypertonic sodium chloride solution. The experiment was performed 6 times on 2 animals, dogs " $A$ " and "G." In Experiment A-3, $100 \mathrm{ml}$. of 1.6 molar sodium chloride were infused. In all other experiments, G-2, 3, 4, 6 and 7, $250 \mathrm{ml}$. of 1.0 molar sodium chloride solution were infused. If sufficient time was allowed for the administration of the infusions ( 45 to 90 minutes), this amount of salt was exceptionally well tolerated and produced no objective signs of physiologic disturbance. If, however, the rate of infusion was reduced to $1 / 4$ hour or less, profound cerebral irritability, clonic convulsions and death occurred.

\section{RESULTS}

Administration of hypertonic salt solution intravenously resulted in acute hypertonia. The molarity of the serum rose rapidly to an average level of 370 milliosmoles and returned to normal in about 7 hours. In all instances, the rise in molarity was followed by a selective increase in the absolute numbers of circulating neutrophiles. The neutrophile rise was statistically significant and of an order of magnitude of 50 per cent or greater. Immediately following the infusion of the hypertonic salt solution, there was a slight decrease in the total numbers of all cell types, both red and white. This was felt to be due to a simple dilution effect from the volume of infused solution and not to be indicative of any specific action on blood cells. Then the rise in absolute numbers of granulocytes began abruptly, around $1 / 4$ to $1 / 2$ hour after the infusion was completed, and reached its highest level in from 7 to 10 hours. In acute hypertonicity, as in chronic, the increase in absolute neutrophile count bore a linear relationship to the increase in molarity of the extracellular fluids (Exp. A-3, Figure 1). Since, with acute hypertonicity, the rise in molarity usually preceded by an hour or more the rise 


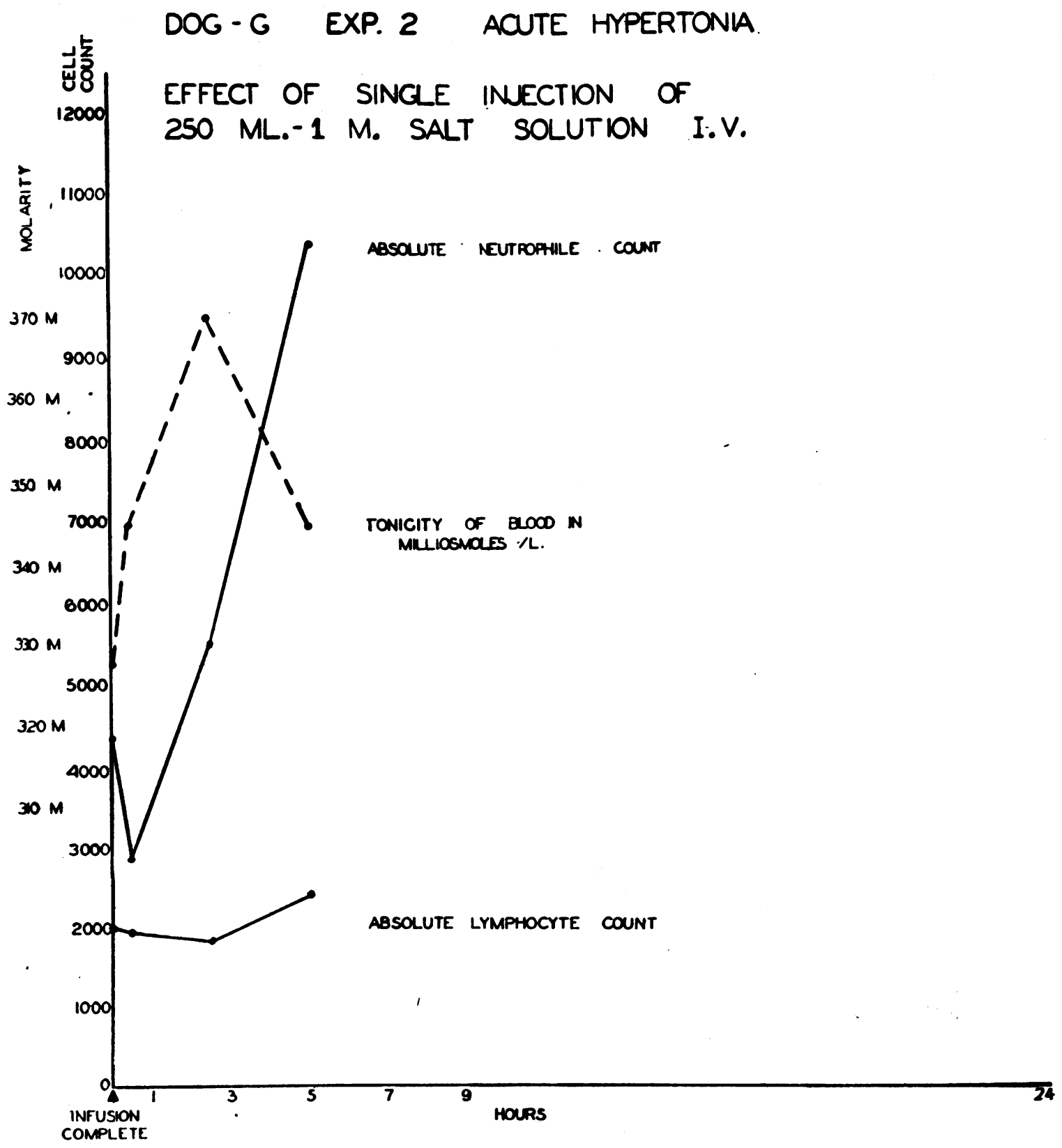

FIG. 3.

in neutrophiles, the fluctuations in count and tonicity are best plotted against time. Thus in Figures 3,4 and 5 , the 24 -hour variation in absolute counts following a single infusion of $250 \mathrm{ml}$. of hypertonic saline may be seen for Experiments G-2, 3 and 4. As a control experiment it was next decided to test the effect of an infusion of a similar amount of isotonic saline to determine how much of the polymorphonuclear rise, if any, could be attributed to a non-specific "washing out" of cells secondary to an increased rate of blood flow. 
In Experiment G-5 (Figure 6), it will be seen that a transitory rise in neutrophile count did occur after isotonic saline. The rise was slight, however, and not sustained. It was felt that part of this rise might be due to splenic contraction from the stimulus of the intravenous infusion. The animal was therefore splenectomized and the experiments repeated, with both isotonic and hypertonic saline.
In Experiment G-8 (Figure 7.), it will be seen that removal of the spleen completely abolished the non-specific rise that occurred in the control injection of isotonic saline. However, in Experiments G-6 and 7 (Figures 8 and 9), it will be seen that removal of the spleen did not affect the rise in count which follows hypertonicity. The rise in neutrophile count, as previously, was

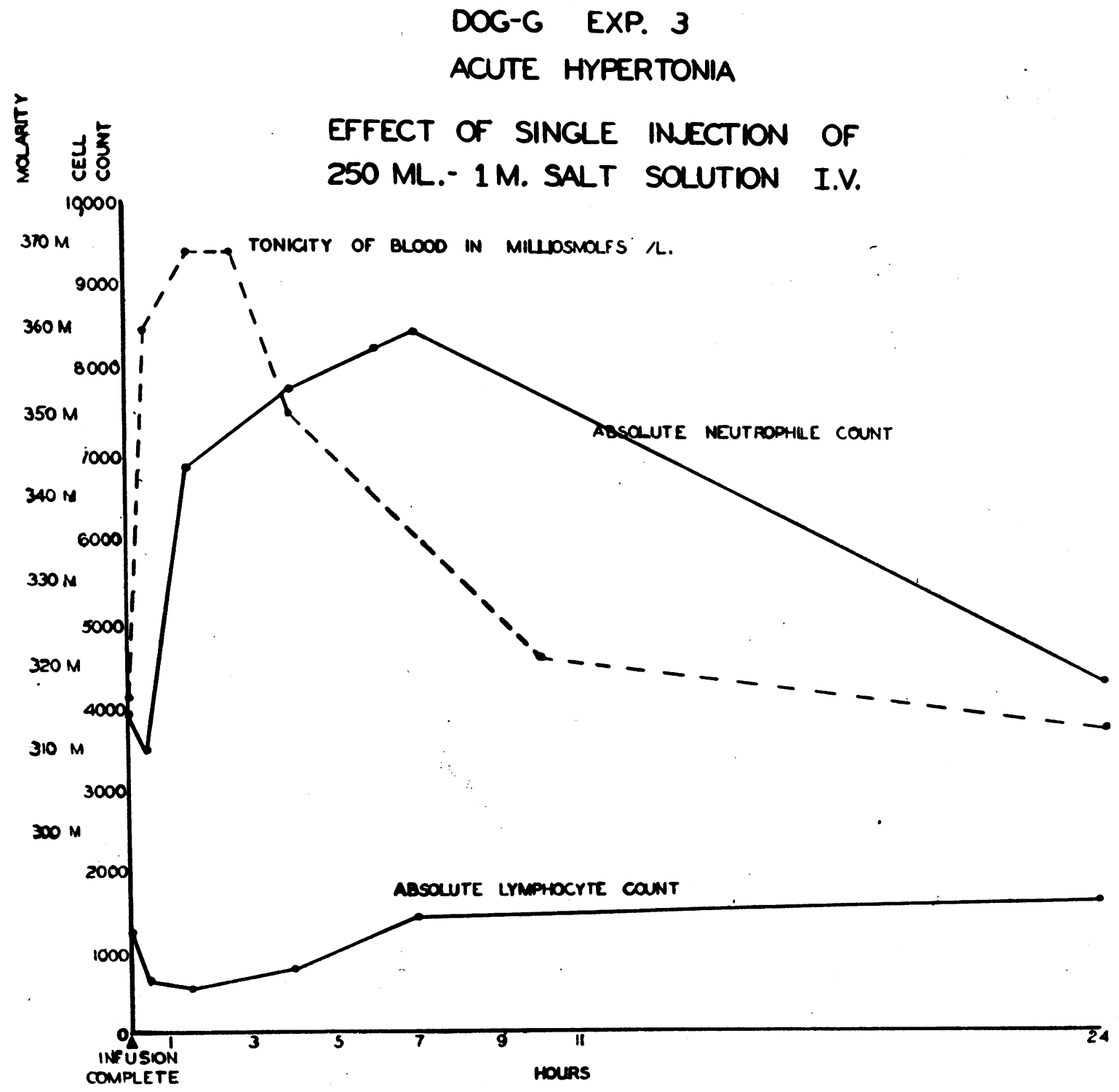

FIg. 4. 


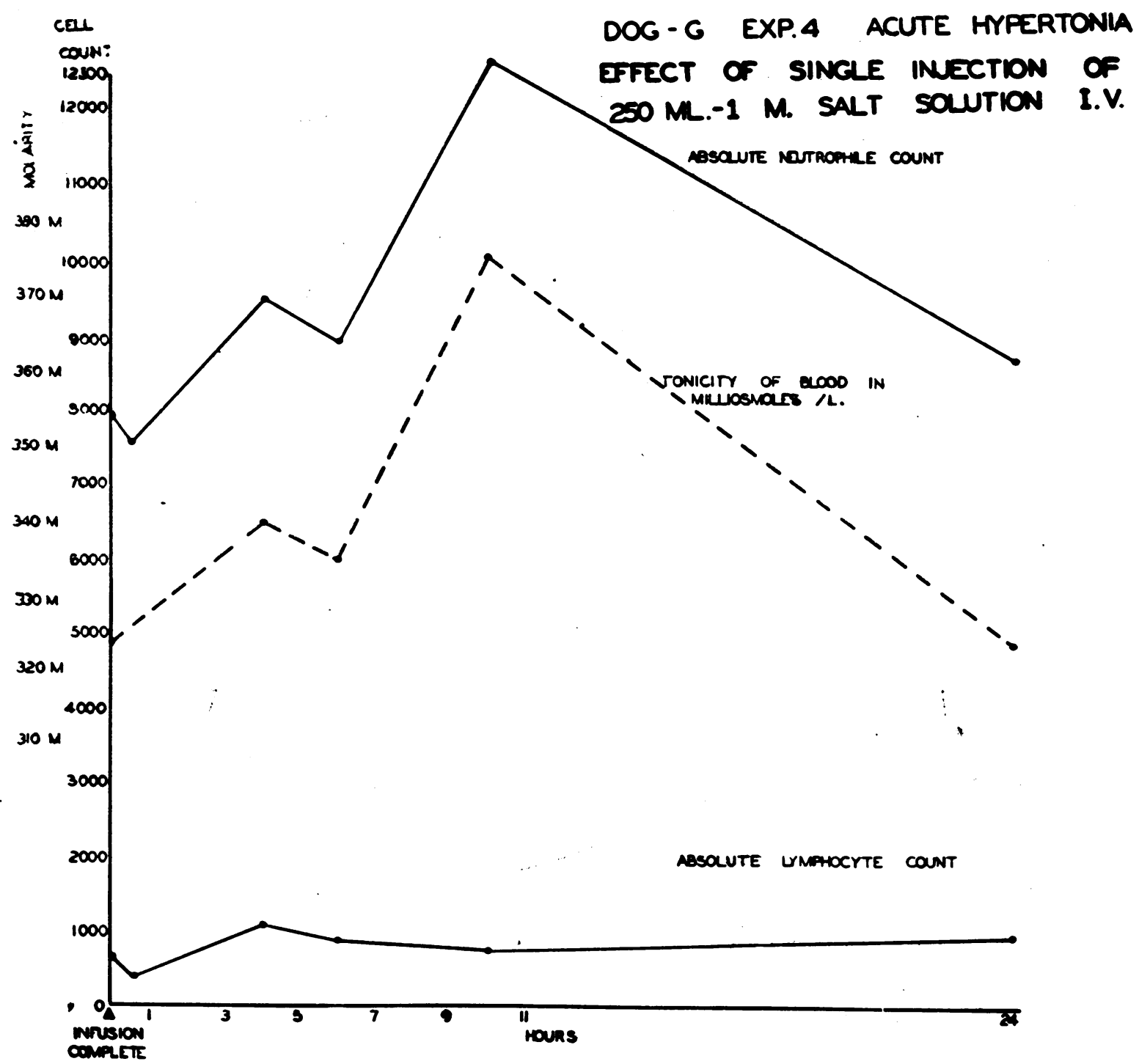

Fic. 5.

prompt, selective (unaccompanied by lymphocytosis) and statistically significant.

\section{DISCUSSION}

Within the limits of these experiments it is reasonable to ascribe a cause and effect relationship between the milliosmolar strength of the serum and the absolute numbers of circulating neutrophiles. Due to the fact that the leukocyte variations in these experiments were produced by alterations in osmotic pressure rather than through the use of foreign proteins or other substances alien to the blood stream, it is not unreasonable to postulate that variations in milliosmolar strength of the extracellular fluids may play a role in determining the leukocyte pattern in some diverse disease states. For example: (1) The unexplained polymorphonuclear leukocytosis which regularly accompanies the hypertonicity of diabetic coma. (2) The unexplained granulopenia and 
relative lymphocytosis which regularly accompanies the hypotonicity of Addison's disease. Studies are currently being carried on to investigate these relationships.

The mode of action of the hypertonic polymorphonuclear leukocytosis produced in these experiments is unknown. Its prompt occurrence in acute hypertonicity makes it obvious that it is not due to the effect which originally stimulated these investigations, namely: The lengthened survival time of neutrophiles in hypertonic media
(11). The recent work of Lawrence (13), who places the in vivo survival time of leukocytes at 16 hours, would similarly tend to make such an effect improbable. The 2 most likely mechanisms would seem to be either a release of preformed cells from some theoretical "store house" in the body or an accelerated maturation and release of immature cells from the bone marrow. If the first mechanism obtains, it would be difficult to visualize the absence of a simultaneous rise in all leukocyte types (lymphocytes, monocytes,

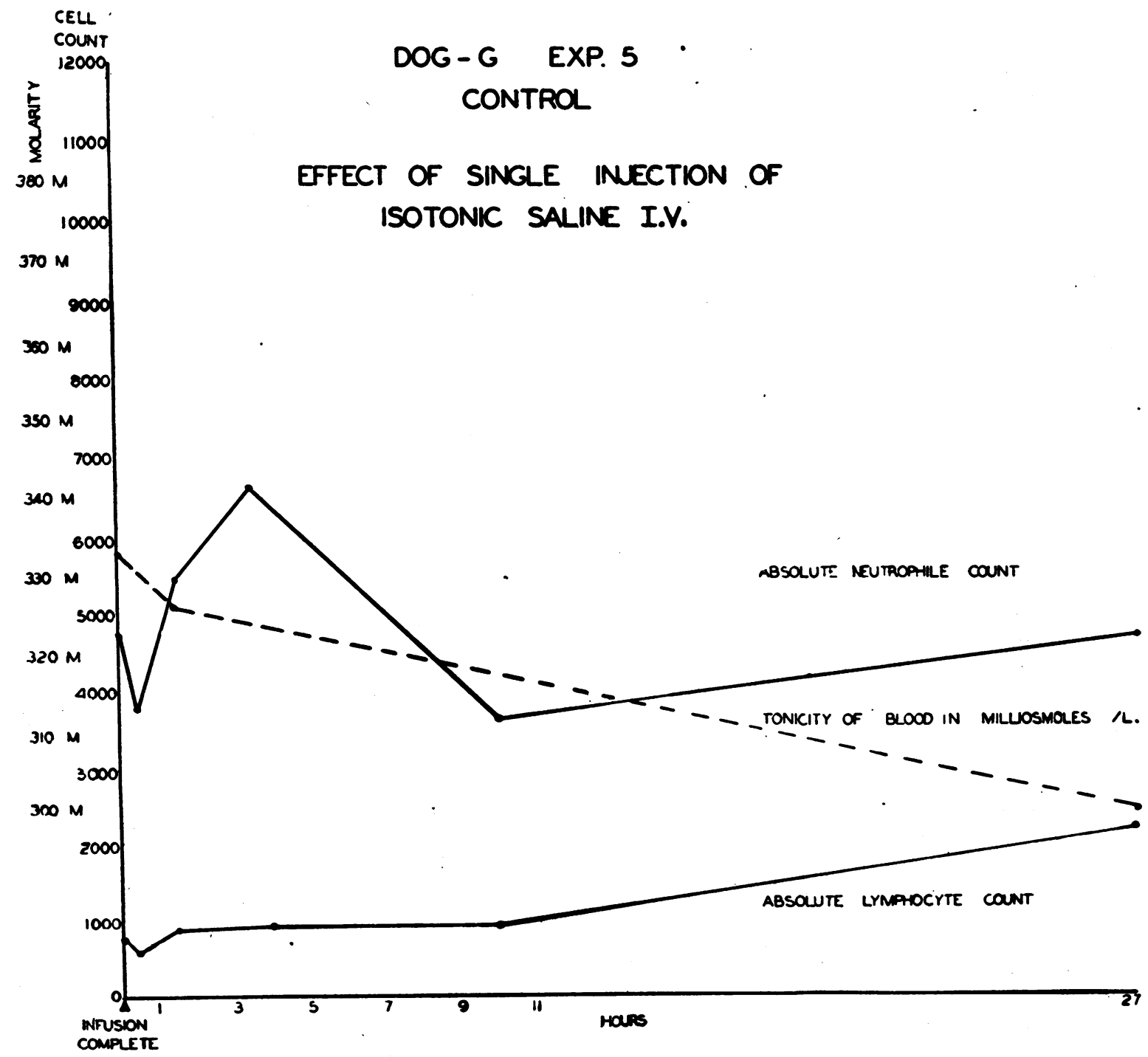

Fra. 6. 


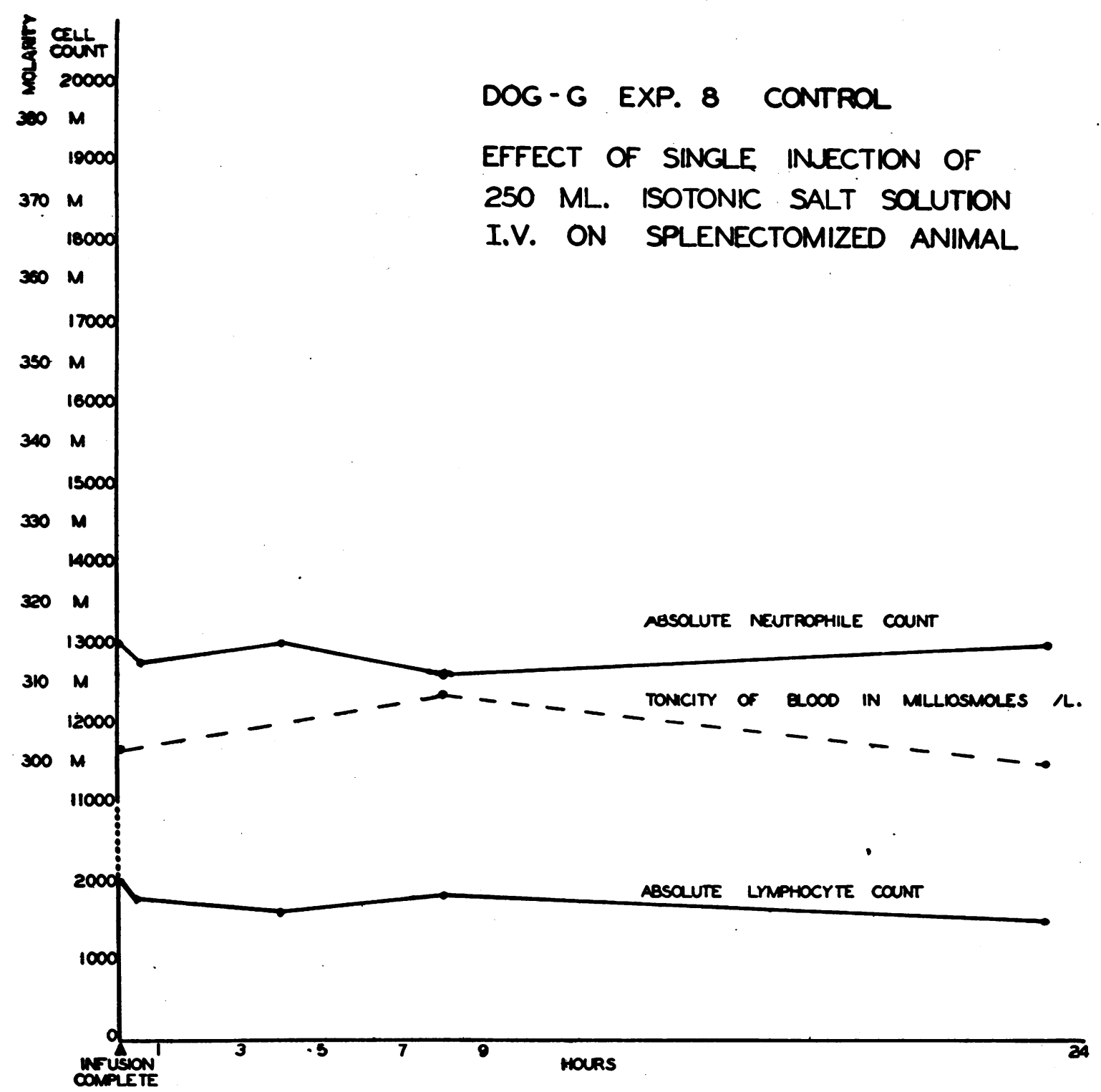

Fic. 7.

eosinophiles) and the persistence of the rise in the case of the chronically induced hypertonicity. If the second mechanism obtains, one would expect rather large numbers of juvenile neutrophiles to appear in the peripheral circulation. Although this phenomenon was looked for, and sometimes found, its appearance was too irregular to lend weight to this possibility. On the basis of these experiments, no explanation of the mechanism can be offered. Further investigation into the mode of action of hypertonic polymorphonuclear leukocytosis should include serial bone marrow observations.

\section{SUMMARY}

Hypertonicity of the serum of dogs was produced both acutely and chronically. In all in- 
stances it was accompanied by relative and absolute increases in the numbers of circulating neutrophiles. The absolute numbers of lymphocytes remained essentially unchanged with increases in molarity. Monocytes, when present in numbers to be statistically significant, showed a slight decrease with increases in molarity.

\section{CONCLUSION}

Under the conditions of these experiments the increases in absolute numbers of circulating neutrophiles were directly proportional to the increases in the milliosmolar strength of the extracellular fluids.

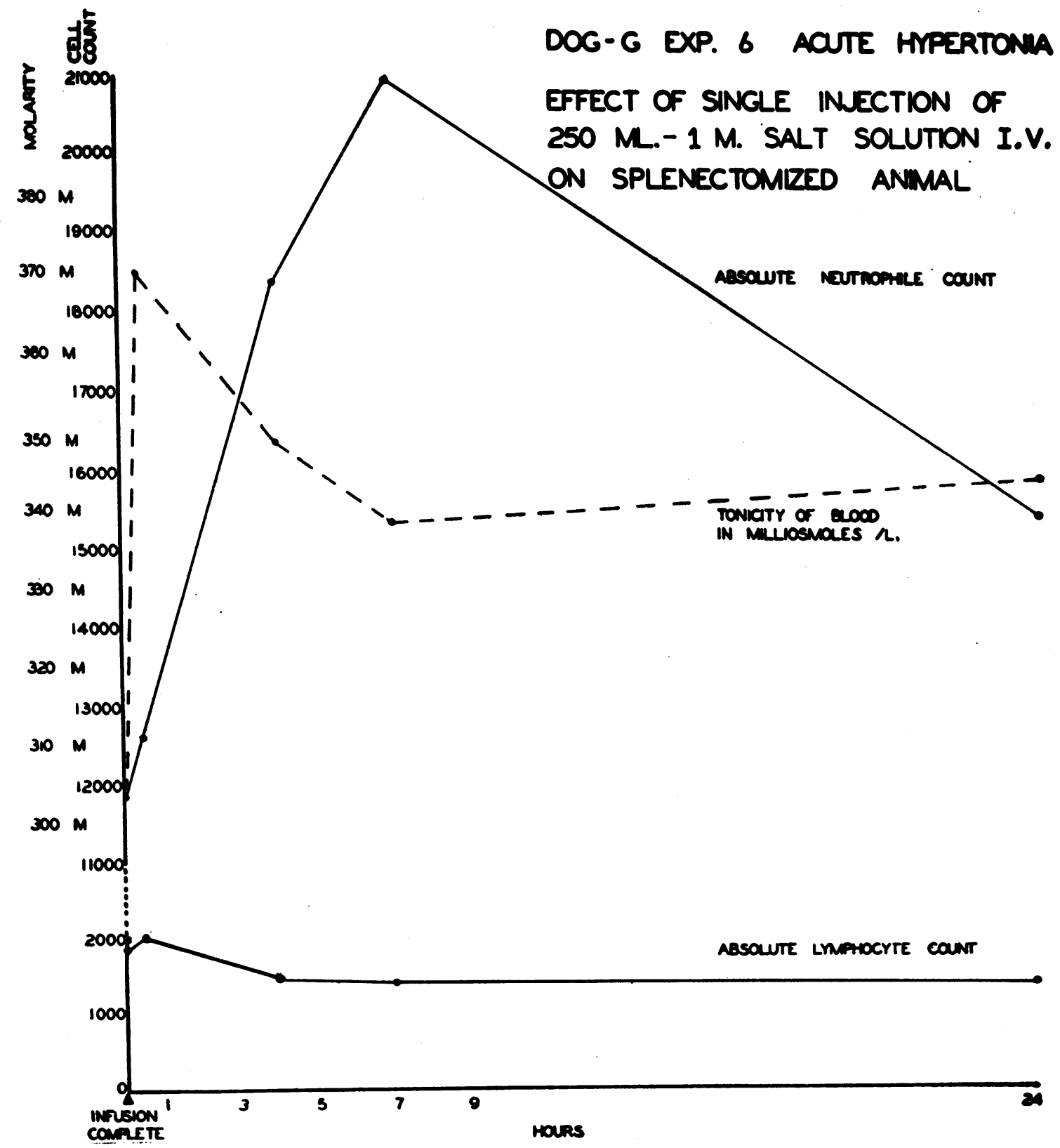

FIG. 8. 


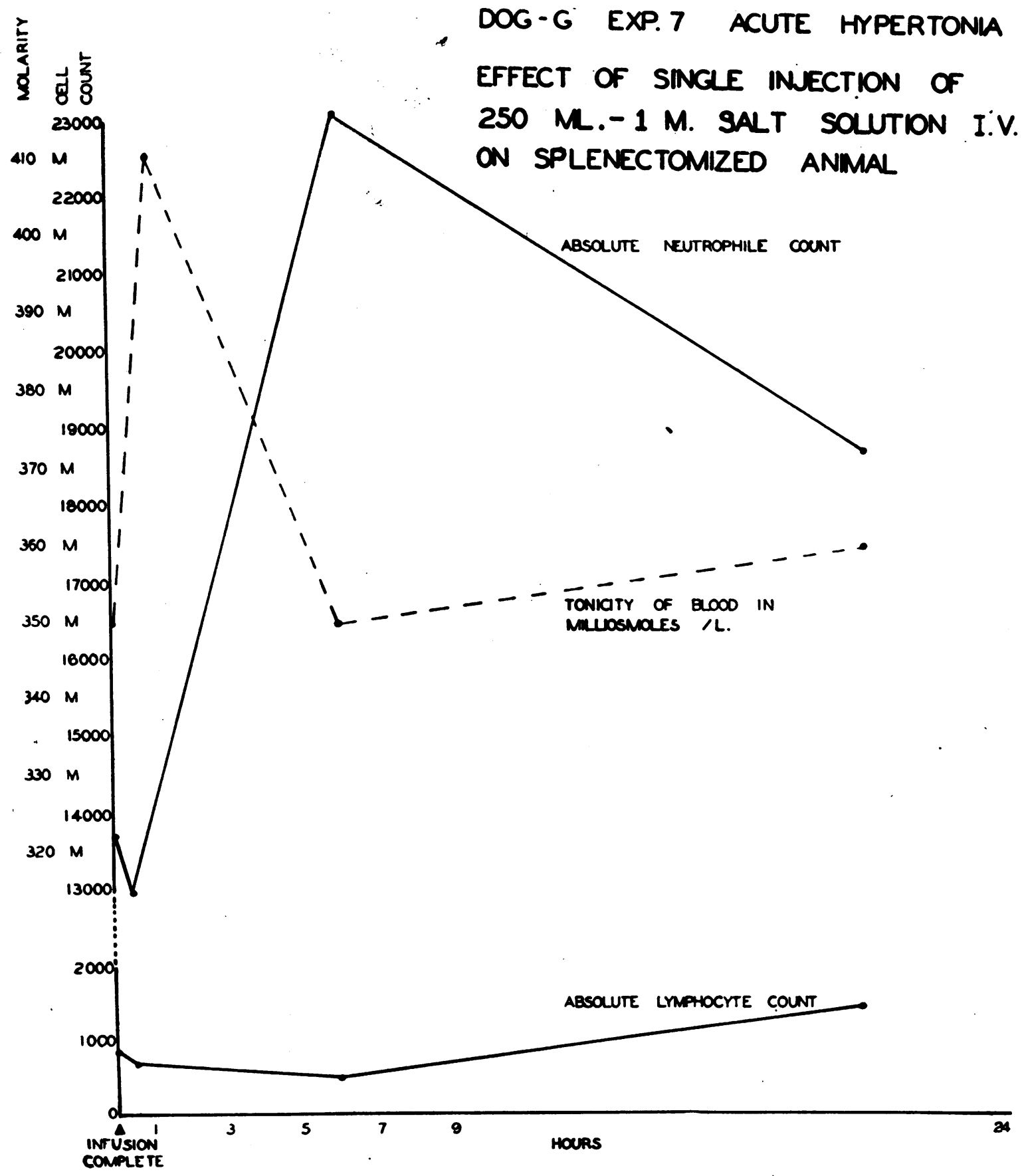

FIG. 9. 


\section{BIBLIOGRAPHY}

1. Ewing, J., Toxic hypoleukocytosis. N. Y. Med. J., 1895, 61, 257.

2. Arneth, J., Die Qualitative Blutlehre, Druck Der Univ Ersitätsdruckerei H-Stürtz. A. G. Würzburg, Leipzig, 1920, 309-321.

3. Ponder, E., and Flint, K. N., Arneth count; effect of various drugs and extracts. Quart. J. Exper. Physiol., 1927, 16, 393.

4. Nettleship, A., Leukocytosis associated with acute inflammation. Am. J. Clin. Path., 1938, 8, 398.

5. Menkin, V., Dynamics of Inflammation. Macmillan, New York, 1940, 110-114.

6. Burnham, F. W. E., Hemocytes and Hemic Infections. New Werner Co., Akron, O., 1913, p. 58.

7. Kennedy, W. P., and Thompson, W. A. R., Studies on Arneth count; deflection of count by ultra-violet rays. Quart. J. Exper. Physiol., 1928, 18, 263.
8. Boyd, W., Leucocytosis produced by the injection of normal saline solution. J. Ment. Sci., 1913, 59, 86.

9. Bluemel, C. S., and Lewis, R., Effect of intravenous saline solution on the leukocyte count. Am. J. Physiol., 1924, 67, 464.

10. Beard, L. A., and Beard, J. W., Effect of intravenous injection of sodium chloride on distribution of white blood cells in peripheral circulation. Am. J. Physiol., 1928, 85, 169.

11. Tullis, J. L., Studies on permeability of the leucocyte. Am. J. Physiol., 1947, 148, 708.

12. Danowski, T. S., Elkinton, J. R., and Winkler, A. W., Deleterious effect in dogs of dry protein ration. J. Clin. Invest., 1944, 23, 816.

13. Lawrence, J. S., Ervin, D. M., and Wetrich, R. M., Life cycle of white blood cells; rate of disappearance of leukocytes from peripheral blood of leukopenic cats. Am. J. Physiol., 1945, 144, 284. 